\title{
Stress dose steroids-take another look at the literature
}

\author{
Henrik Kehlet, MD, PhD
}

Received: 13 February 2020/Revised: 13 February 2020/ Accepted: 6 March 2020/Published online: 16 March 2020

(c) Canadian Anesthesiologists' Society 2020

\section{To the Editor,}

Once again, a debate surrounding "stress dose steroids" has re-emerged ${ }^{1}$ emphasizing the lack of robust data despite several reviews. Being personally involved in some of the original research addressing potential secondary adrenal insufficiency in glucocorticoid-treated surgical patients, I am a little surprised that the discussion is never based on the (admittedly) old physiologic data that provided a rational treatment regimen based on both physiologic steroid levels and those measured in normal patients undergoing minor and major surgery. ${ }^{2}$ Such steroid supplementation proposals were based on detailed isotopic cortisol turnover studies in major surgery ${ }^{3}$ showing that approximately $150 \mathrm{mg}$ of cortisol was secreted during these major procedures thus providing a physiologic basis for how to supplement. Furthermore, the proposed regimen was supported by detailed repeated blood sample measurements in adrenalectomized patients. ${ }^{4}$

This area of research started with case reports of acute secondary adrenocortical insufficiency in surgical patients on glucocorticoid therapy; however, more detailed studies almost 50 years ago showed that this was very rare, despite partial cortisol deficiency. ${ }^{5}$

In summary, the discussion as to how to supplement using physiologic cortisol administration in surgical stress situations in patients with partial or total adrenal insufficiency should be argued based on these past

This letter is accompanied by a reply. Please see can J Anesth 2020; 67: this issue.

H. Kehlet, MD, PhD (ه) .

Section of Surgical Pathophysiology, Rigshospitalet,

Copenhagen University, Copenhagen, Denmark

e-mail: henrik.kehlet@ regionh.dk detailed studies. This can lead to recommendations based on physiologic dosing regimens that are both simple and safe.

Conflicts of interest None.

Funding statement None.

Editorial responsibility This submission was handled by Dr. Hilary P. Grocott, Editor-in-Chief, Canadian Journal of Anesthesia.

\section{References}

1. Urmson K. Stress dose steroids: the dogma persists. Can J Anesth 2020; 67: 276-7.

2. Kehlet $H$. A rational approach to dosage and preparation of parenteral glucocorticoid substitution therapy during surgical procedures. A short review. Acta Anaesthesiol Scand 1975; 19: 260-4.

3. Kehlet $H$, Binder $C$. Alterations in distribution volume and biological half-life of cortisol during major surgery. J Clin Endocrinol Metab 1973; 36: 330-3.

4. Kehlet $H$, Binder $C$, Blichert-Toft $M$. Glucocorticoid maintenance therapy following adrenalectomy: assessment of dosage and preparation. Clin Endocrinol (Oxf) 1976; 5: 37-41.

5. Kehlet $H$, Binder $C$. Adrenocortical function and clinical course during and after surgery in unsupplemented glucocorticoid-treated patients. Br J Anaesth 1973; 45: 1043-8.

Publisher's Note Springer Nature remains neutral with regard to jurisdictional claims in published maps and institutional affiliations. 